\title{
El ingreso universitario: notas sobre el revés de una trama compleja
}

María del Rosario Badano (1), María Gracia Benedetti (2), María Alfonsina Angelino (2), Ruth Lemos ${ }^{(2)}$, Valeria Rodrigo ${ }^{(2)}$
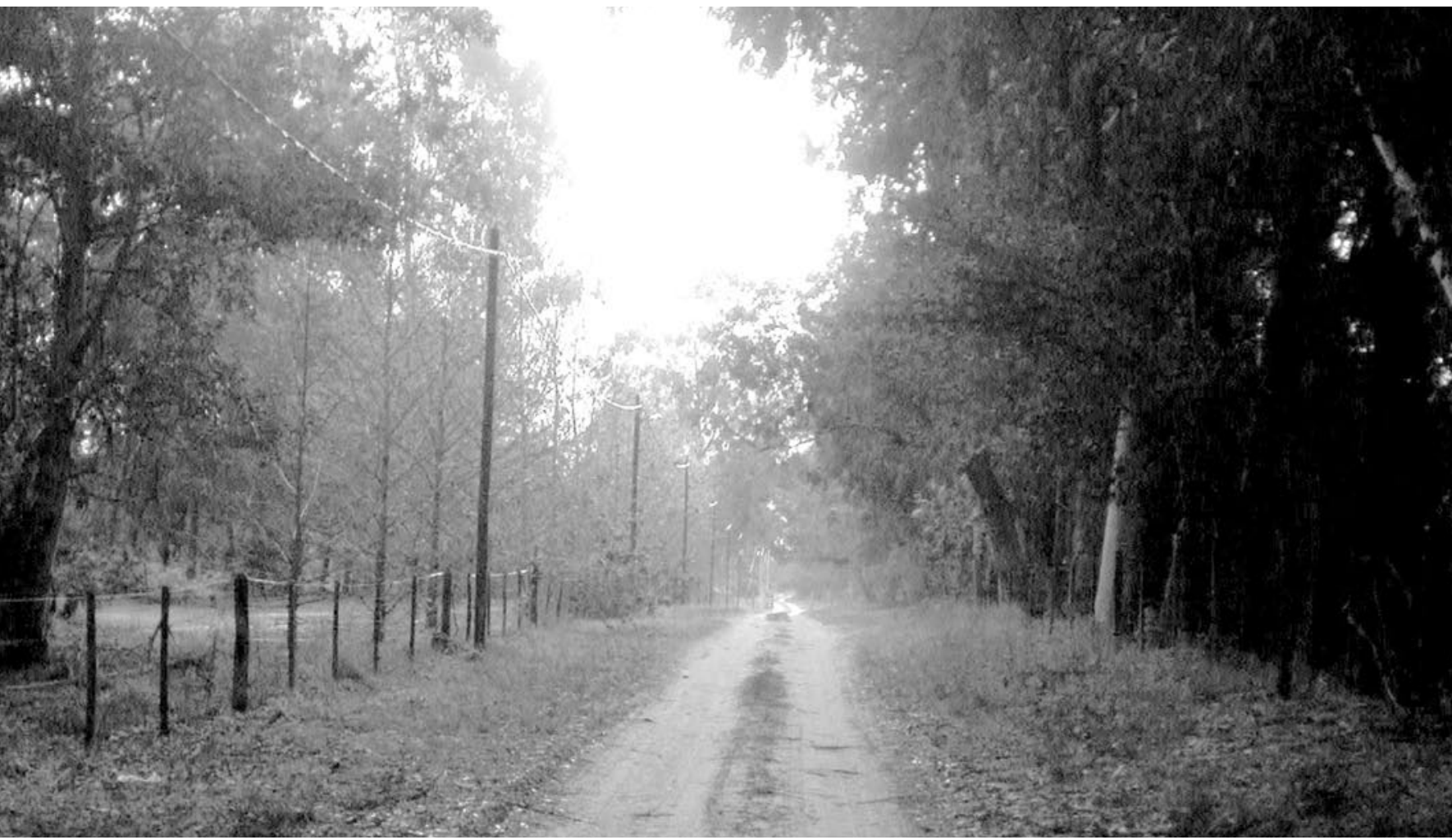

(1) Asesora Pedagógica Facultad de Trabajo Social. Docente e investigadora de la FTS-UNER y de la UADER.

E-mail: mbadano@gigared.com
(2) Docentes de la Facultad de Trabajo Social, Asesoría Pedagógica, UNER. 
(3) Mircea Eliade (1983): Mito y Realidad, Edit. Labor, Punto Omega, 5 Edición, Barcelona, p. 147.
Existen múltiples perspectivas de análisis acerca del tema del ingreso universitario que ponen énfasis en aspectos específicos y presentan a su vez diferentes lecturas de los problemas.

Nos interesa reflexionar aquí acerca de los mitos y significados que se construyen en torno del ingreso que recorren y forman parte de la cultura de la universidad pública.

Los mitos -creencias que se sostienen como verdaderas- ordenan e informan acerca de la realidad transformándose en certezas absolutas. Tan pronto enuncian e informan como desvirtúan y ocultan.

Se considera que los mitos, con sus cargas de representaciones recorren la escena universitaria, modelan discursos e impregnan prácticas pedagógicas y sociales constituyendo sujetos y saberes.

Mircea Eliade (1983), sostiene que los mitos son creencias que la gente sostiene como verdades:

"El mito es una forma eficaz de combatir la fugacidad y la caducidad de lo humano. Es una realidad y hay que contar con ella no sólo como imagen del pasado, sino también como técnica del hombre moderno para analizar el presente. Los mitos constituyen valores absolutos, paradigmas de todas las actividades humanas, y estos modelos son transmitidos socialmente."(3)

El mito le garantiza al hombre que lo que se dispone a hacer ya ha sido hecho, le ayuda a borrar las dudas que pudiera concebir sobre el resultado de su empresa. No es, en si mismo, una garantía de "bondad" ni de moral. Su función es revelar modelos, proporcionar así significaciones.

Nuestro propósito es identificar algunos de estos mitos para reflexionar acerca de ellos, de los significados que se construyen en torno del ingreso que recorren y forman parte de la cultura de la universidad pública. Este pensamiento mítico se encuentra presente de distintas maneras en los sujetos que participamos en el proceso del ingreso: los docentes universitarios, los jóvenes ingresantes, las familias, entre otros.

Nos interesa comenzar a trabajar en este espacio tomando dos construcciones 
de sentido que condensan o reflejan parte de la complejidad de la problemática. En una primera instancia presentaremos la tensión acerca de la idea de adaptación a la universidad como responsabilidad individual del estudiante y la idea de la responsabilidad política de la universidad en el ingreso.

Así es común escuchar "A los 18 años, una vez terminada la escuela secundaria, todos los jóvenes están preparados para ir a la universidad. Y si fracasan es porque no estudian. Todos los estudiantes se deben 'adaptar' a la universidad".

Estos enunciados remiten a lecturas sociales que tienden a ocultar las dificultades que recorren la formación de la enseñanza secundaria; generaliza y naturaliza las diferencias en los grupos de estudiantes. Hablar sólo de la irresponsabilidad de los jóvenes ante los fracasos masivos en los exámenes de ingreso sería desconocer la complejidad e historicidad del tema y clausurar su tratamiento a una perspectiva que culpabiliza a los estudiantes y elude su dimensión político pedagógica.

Por ello no es posible debatir la problemática del ingreso en un vacío histórico y político, ya que el contexto social y educativo es constitutivo del problema que nos ocupa. Por lo que no basta describir lo social e histórico inscripto en la universidad sin intentar otras condiciones y respuestas. El problema del ingreso tiene historicidad a veinte y tantos años de democracia. Por lo tanto discutir el ingreso ha implicado discutir políticas de conocimiento, el sentido de lo público y la responsabilidad social de la universidad. La heterogeneidad de marcas relativas, las huellas de la exclusión social y económica, en cuanto a capital social y cultural, y a la pobreza, pueden reconocerse en los sujetos y las prácticas.

Históricamente, las cuestiones vinculadas a lo que se ha denominado la problemática de los ingresantes o del ingreso han sido entendidas más como de adaptación de sujetos -tanto de los estudiantes como de los docentes e instituciones- y no como procesos relacionales complejos, tensionales, en los que se disputan saberes, historias, intereses, necesidades. Estas relaciones se construyen y reconstruyen y se traducen en prácticas (y discursos) de enseñanza y aprendizaje particulares. Allí operan y se juegan campos de representaciones sociales que estudiantes y docentes tienen acerca de la profesión o disciplina, de lo que implica ser universitario, entre otras. 
El abandono y la deserción en los primeros años de carrera, muchas veces, se dan por este "no aprendizaje del oficio", esta no adaptación a las nuevas reglas de juego, las nuevas normas del "hacer "y ser universitario".

Este aprendizaje del oficio de estudiante se vincula con la apropiación del sujeto de las reglas del juego institucionales y supone un aprendizaje que, en general, ningún agente institucional explicita. No se advierte que las dimensiones institucionales, los modos de habitar, sean saberes a transmitir.

Las experiencias personales, familiares, tienen peso a la hora de manejar estos nuevos códigos y reglas, la historia cultural, pedagógica y social, juegan y se juegan en este tránsito de los sujetos.

Es central tener en cuenta, que la responsabilidad en el proceso de aprendizaje del oficio no puede quedar librada a las experiencias personales y sociales de origen de los alumnos.

Este oficio supone un juego complejo en el que están presentes en la configuración de una cultura institucional y la cultura académica particular que requiere de diferentes tiempos. Si el ingresante, en la caracterización que se realiza, es este otro cada vez más extraño, más diferente al que yo era en ese momento, se ingresa en un circuito de no entendimiento que comienza con la rareza, se le suma la sospecha de quién es este otros, se torna no solo misterioso, sino académicamente vulnerable.

Resulta central el conocimiento del ingresante en cuanto a quién es, conocimiento, habilidades, representaciones. Elaborar un mapa de la composición de la matrícula que posibilite puntos comprensivos superando el listado de carencias que no solo refuerzan la mirada ya conocida sino que también se alejan cada vez más de mantener estudiantes y docentes una relación pedagógica significativa.

En la segunda tensión trabajamos la idea de pasaje "natural" del estudiante de la escuela media a la universidad y el concepto del ingreso como proceso de ruptura epistemológica y cultural.

Consideramos que el ingreso a la universidad es una experiencia histórica significativa en la vida del sujeto, ya que el pasaje de una institución de educación secundaria a otra de nivel superior genera una suerte de ruptura epistemológica que condensa transformaciones a nivel de las subjetividades de los protagonistas. Estas transformaciones se refieren tanto a los cambios en 
las normas de convivencia y desempeño de los alumnos en la universidad como la incorporación de nuevas y específicas formas de relación con el conocimiento.

Los que ingresan a la universidad son en su mayoría adolescentes, que vienen de clausurar una etapa de la vida para abrir otra. De esta manera, en su inscripción a la universidad, los jóvenes adolescentes se inscriben también en un proyecto de estudio, trabajo, y comienzan la inserción en la vida social más amplia.

Por lo tanto la entrada en la vida universitaria implica pasar del rango de alumno del secundario al de estudiante universitario y que como todo tránsito requiere una tarea de iniciación, de aprendizajes, de adaptaciones, desestructuraciones y nuevas estructuraciones.

Lo conocido para los alumnos y alumnas es la dinámica, las relaciones, los ritos, las reglas, de la escuela secundaria que los ha contenido y con la que ha entablado una relación significativa y peculiar. Los jóvenes se encuentran con que las estrategias y herramientas intelectuales, cognitivas, afectivas, que antes le resultaron exitosas, no son homologables a las necesarias para el desarrollo del oficio de estudiante universitario. Oficio que será necesario aprender, en la construcción de la ciudadanía universitaria.

En este sentido los estudiantes entre la escuela media y la universidad realizan mucho más que un simple pasaje, se produce una ruptura (Del lat. rompimiento; desavenencia o disputa, rotura.)

A su vez usamos este concepto para referir al proceso de pasaje de las nociones del sentido común por una primera noción científica ${ }^{(4)}$, romper las relaciones más aparentes para hacer surgir el nuevo sistema de relaciones entre los elementos. A su vez el concepto de obstáculo epistemológico que trabaja Gastón Bachelard remite al conflicto cognitivo que se presenta en el sujeto, desequilibrio, choque entre las prenociones, prejuicios, costumbres, la opinión, los conocimientos previos y la posibilidad de construir conocimientos nuevos.

Estas acepciones hacen referencia a una acción o movimiento, a un costo que hay que pagar, trayecto que hay que pasar, camino por el que se transita. Se habla también de una contención que se hace de alguien. Aparece la idea de lo público en el concepto de pasaje, como trascendiendo
(4) Maus, citado por Pierre Bordieu en "El oficio del sociólogo", 1994. 
la connotación individual. Y por último está presente la idea de cambio, que implica la noción de conflicto y ruptura presente en el choque epistemológico y cultural.

Se alude a un proceso complejo que compromete un tratamiento específico desde la institución y que desafía a la pedagogía universitaria en cuanto a los modos de organizar una propuesta crítica que posibilite construir un campo de trabajo político académico en común.

Los jóvenes que ingresan a la Universidad Nacional de Entre Ríos pertenecen a diferentes escenarios culturales. Tales escenarios reconocen en algunos casos, marcas de exclusiones en lo social y económico.

Se adjudican los problemas en el cursado a carencia de habilidades mentales o al bajo coeficiente intelectual como características individuales. En estas concepciones se deja de lado la reflexión acerca de la cultura escolar.

Desde otra perspectiva, las dificultades cognitivas, de habilidades y de formación de los estudiantes que ingresan, es necesario reconocerlas y abordarlas con propuestas innovadoras, dado que uno de los aspectos que inciden en este perfil es la cultura escolar tradicional, que trabaja sobre fragmentos aislados de conocimiento y sobre aprendizaje memorístico de datos ritualizados y segmentados. (Boscaroll-Ingaramo, UNL, 1995)

En este sentido es necesario plantear los procesos de "alfabetización académica" aludiendo a los trayectos de enseñanza de las prácticas de lenguaje y pensamiento de una comunidad científica o profesional por el cual los sujetos ingresan a esa cultura. Algunas reflexiones para seguir pensando.

Los fundamentos que se ponen en juego para la puesta en marcha de dispositivos de ingreso universitario se articulan en torno al desafío de constituir puentes, instancias pedagógicas mediadoras entre esta cultura de los ingresantes y la cultura académica universitaria y de la disciplina.

Es indispensable entonces, problematizar acerca de los discursos hegemónicos que sitúan a la universidad como un punto de llegada, como meta a alcanzar y no como trayecto de formación a transitar de conjunto, como encuentro, en definitiva en un punto de partida.

La función social amplia implica reconocer a la universidad como espacio social y político capaz de producir efectos sobre sí mismo y sobre otros espacios con los cuales se co-implica (el contexto, la escuela media y la articulación 
entre niveles). Pero esta función social demanda una reorganización del campo para poder pensar lo que antes era impensable, transitar en el desafío de democratizar incluyendo, incluir con calidad, construir ciudadanía.

Referencias bibliográficas.

Díaz, E. (1998): La ciencia y el imaginario social, Editorial Biblos, Bs. As.

Eliade, M. (1998): Mito y realidad, Editorial Labor - Punto Omega, $5^{\circ}$ Edición, Barcelona, España.

Foucault, M. (1997): Las palabras y las cosas: una arquelogía de las Ciencias Humanas, Edit. S. XXI, Edición en español, México. 